Correction

\title{
Correction: Kovács, K.; Kovács, K.E. Using the Behavioural Regulation in an Exercise Questionnaire (BREQ-2) in Central and Eastern Europe: Evidence of Reliability, Sociocultural Background, and the Effect on Sports Activity. Int. J. Environ. Res. Public Health 2021, 18, 11834
}

\author{
Klára Kovács ${ }^{1}$ and Karolina Eszter Kovács ${ }^{2, *}$ \\ 1 Institute of Educational Sciences and Cultural Management, Faculty of Arts, University of Debrecen, \\ 4032 Debrecen, Hungary; kovacs.klara@arts.unideb.hu \\ 2 Institute of Psychology, Faculty of Arts, University of Debrecen, 4032 Debrecen, Hungary \\ * Correspondence: kovacs.karolina@arts.unideb.hu
}

check for

updates

Citation: Kovács, K.; Kovács, K.E.

Correction: Kovács, K.; Kovács, K.E.

Using the Behavioural Regulation in an Exercise Questionnaire (BREQ-2)

in Central and Eastern Europe:

Evidence of Reliability, Sociocultural

Background, and the Effect on Sports

Activity. Int. J. Environ. Res. Public

Health 2021, 18, 11834. Int. J. Environ.

Res. Public Health 2022, 19, 1178.

https://doi.org/10.3390/ijerph

19031178

Received: 15 December 2021

Accepted: 16 December 2021

Published: 21 January 2022

Publisher's Note: MDPI stays neutral with regard to jurisdictional claims in published maps and institutional affiliations.

Copyright: (c) 2022 by the authors. Licensee MDPI, Basel, Switzerland. This article is an open access article distributed under the terms and conditions of the Creative Commons Attribution (CC BY) license (https:// creativecommons.org/licenses/by/ $4.0 /)$.

\section{Missing Funding}

In the original publication [1], funding from the "University of Debrecen Faculty of Humanities Scholarly Fund" to "Klára Kovács and Karolina Eszter Kovács" was not included. Thus, the correct Funding statement is the following:

Funding: This research is project no. 123847, supported through National Research, Development and Innovation, financed from the K_17 application program, and published with the support of a János Bolyai Research Scholarship (2016-2019). The publication was supported by the University of Debrecen Faculty of Humanities Scholarly Fund.

The authors apologize for any inconvenience caused and state that the scientific conclusions are unaffected. The original publication has also been updated.

\section{Reference}

1. Kovács, K.; Kovács, K.E. Using the Behavioural Regulation in an Exercise Questionnaire (BREQ-2) in Central and Eastern Europe: Evidence of Reliability, Sociocultural Background, and the Effect on Sports Activity. Int. J. Environ. Res. Public Health 2021, 18, 11834. [CrossRef] [PubMed] 